\title{
Os areais do sudoeste do Rio Grande do Sul, Brasil, como patrimônio geomorfológico
}

\author{
The sand areas in southwest Rio Grande do Sul, Brazil, as a \\ geomorphological heritage
}

Sidnei Luís Bohn Gass, Universidade Federal do Pampa e Programa de Pós-Graduação em Geografia, Universidade Federal do Rio Grande do Sul, Brasil, sidneibohngass@gmail.com

(1) http://orcid.org/0000-0001-5197-7506

Roberto Verdum, Programa de Pós-Graduação em Geografia e Programa de Pós-Gradução em Desenvolvimento Rural, Departamento de Geografia, Universidade Federal do Rio Grande do Sul, Brasil, verdum@ufrgs.br

(1D) https://orcid.org/0000-0002-0528-4343

Lucimar de Fátima dos Santos Vieira, Departamento Interdisciplinar do Campus Litoral Norte, Universidade Federal do Rio Grande do Sul, Brasil, lucimar.vieira@ufrgs.br

(1) https://orcid.org/0000-0003-4794-9056

Jean Carlo Gessi Caneppele, Doutorando em Geografia, Programa de Pós-Graduação em Geografia, Universidade Federal do Rio Grande do Sul, Brasil, jeancaneppele@yahoo.com.br

(1) https://orcid.org/0000-0002-8487-7533

François Laurent, Laboratoire Espace Société (ESO), Le Mans Université, França, francois.laurent@univ-lemans.fr

(1) https://orcid.org/0000-0002-3833-2022

Resumo: Os processos de arenização encontrados no sudoeste do RS, Brasil, são um fenômeno único, localizado entre as unidades geomorfológicas da Escarpa do Planalto de Uruguaiana e a Depressão Periférica. Os areais se constituem como produto do intemperismo destas formações e que Ihes confere uma condição geomorfológica particular. O presente trabalho tem por objetivo estabelecer relações entre a arenização, seu aproveitamento turístico enquanto patrimônio geomorfológico e os conflitos ambientais ocasionados pelo modelo econômico dominante. Dentre os areais que podem ser identificados na região, o do Cerro da Esquina possui condições de exploração turística, pois permite que parte da "memória da Terra" seja compreendida a partir da sua observação. O potencial dos areais enquanto patrimônio geomorfológico para o desenvolvimento do turismo pode ser avaliado a partir de diferentes aspectos: (i) a compreensão do próprio processo, ou seja, o que são os areais e como surgiram; (ii) a sua vinculação no contexto da bacia hidrográfica do arroio Inhacundá, dentro da qual, se passa por diferentes compartimentos, até chegar aos relevos testemunhos, associados às formações sedimentares (Botucatu e Guará), aos areais e às turfeiras nos fundos dos vales de seus tributários; e (iii) a beleza cênica do conjunto paisagístico da região. Nesta perspectiva, questiona-se a implantação da monocultura silvícola, a qual interfere no processo de conservação do patrimônio geomorfológico, reduzindo o potencial geoturístico apresentado pela região.

Palavras-chave: Arenização; Belezas cênicas; Geoturismo; Uso da terra.

Abstract: The sandisation processes found in southwestern RS, Brazil, are a unique phenomenon, located between the geomorphological units of the Uruguaiana Plateau Escarpment and the Peripheral Depression. The sand areas are a product of the weathering of these formations and give them a particular geomorphological condition. The present work aims to establish relationships between the processes of sandisation, its tourist use as a geomorphological heritage and the environmental conflicts caused by the dominant economic model. Among the sand areas that can be identified in the region, Cerro da Esquina has conditions of tourist exploration, because it allows part of the "memory of the earth" to be understood from its observation. The potential of sand areas as a geomorphological heritage for tourism development can be assessed from different aspects: (i) understanding of the process itself, 
ie what sand areas are and how they arose; (ii) its connection in the context of the Inhacundá stream watershed, within which it passes through different compartments, until reaching the reliefs associated with the sedimentary formations (Botucatu and Guará), the sands and the peat bogs at the bottom of the valleys of its tributaries; and (iii) the scenic beauty of the landscape set of the region. In this perspective, the implementation of forestry monoculture is questioned, which interferes with the process of conservation of geomorphological heritage, reducing the geotourism potential presented by the region.

Keywords: Sandisation; Scenic beauties; Geotourism; Land use.

\section{Introdução}

O estado do Rio Grande do Sul, Brasil, possui uma tradição turística que pode ser visualizada através da Regionalização Turística atualizada em 2017 (SEC-RS, 2017), a qual é composta por 27 regiões, abrangendo boa parte dos municípios que compõe o seu território. Contudo, o grande destaque pode ser dado à Região das Hortênsias e da Uva e do Vinho, pela inserção e pelo reconhecimento no mercado turístico nacional e internacional. As demais regiões possuem amplo potencial turístico, mas estão fora dos grandes mercados turísticos e, muitas vezes, prejudicadas pela infraestrutura de acesso e circulação.

Segundo a mesma Regionalização Turística, os municípios com ocorrência da arenização estão majoritariamente inseridos na Região da Fronteira Oeste associada à vegetação herbácea e às tradições estancianas relacionadas à pecuária. Além disso, municípios como Maçambará, RS, e Unistalda, RS (que possuem focos da arenização e são fronteiriços a São Francisco de Assis), não estão inseridos em nenhuma regionalização, abrindo espaço para políticas públicas de valorização deste patrimônio geomorfológico.

As discussões relacionadas ao geoturismo e à geoconservação no Rio Grande do Sul (RS) são relativamente recentes. Como um dos marcos para estas discussões, podem ser mencionados os trabalhos de Schobbenhaus et al. (2002), Winge et al. (2009) e Winge et al. (2013), que apresentam um levantamento dos Sítios Geológicos e Paleontológicos do Brasil, e que possuem potencial para o geoturismo e a geoconservação. Por sua vez, a obra de Schobbenhaus e Silva (2012) apresenta 17 propostas de geoparques para o Brasil, dentre as quais três estão no RS. A partir desta sistematização, outras produções (Ziemann, Figueiró, 2017; Figueiró et al. 2018) buscam aprofundar a discussão, em especial sobre: a proposta do geoparque da Quarta Colônia, na região central do RS; a proposta do geoparque Guaritas Minas do Camaquã (Peixoto, 2015; Peixoto, 2017), que vem sendo amplamente discutida com a comunidade regional; e a proposta do Geoparque Caminhos dos Cânions do Sul, localizado na divisa dos estados do Rio Grande do Sul e Santa Catarina.

Várias são as abordagens que podem ser adotadas para definir a atividade do geoturismo, como demonstra o resgate feito por Mansur (2018). Para fins do presente estudo, entende-se que a definição apresentada por Newsome e Dowling (2006) atende às discussões e propostas apresentadas, pois estabelece que o geoturismo 
relaciona geologia, geomorfologia, recursos naturais e seus processos de evolução com o turismo, que, por sua vez, envolve a visitação, de modo a gerar nas pessoas um sentimento de interesse, apreciação e entendimento, como sistematizou Mansur (2018). O sentimento de interesse, apreciação e entendimento pode ser vinculado tanto às belezas cênicas quanto à geoconservação. Quanto às belezas cênicas, Vieira (2014) afirma que são importantes como parâmetros à proteção da natureza e do patrimônio da humanidade, no planejamento e na gestão ambiental, pois garantem a permanência das paisagens, da geodiversidade e sobretudo da conservação da biodiversidade, de habitats e ecossistemas. A indicação de paisagens portadoras de belezas cênicas é importante para preservar, conservar e restaurar o patrimônio cultural e natural, além de trazer benefícios econômicos e sociais, como reafirmam Vieira e Verdum (2019). Ainda, de acordo com Bétard et al. (2017a, 2017b), a geoconservação é baseada sobre objetos geológicos ou geomorfológicos considerados como notáveis ou mesmo excepcionais e que são objetos de um processo de "patrimonialização".

Por sua vez, a geoconservação, conforme Sharples (2002), sistematizado por Mansur (2018), visa preservar a geodiversidade relacionada aos importantes processos e feições geológicas, geomorfológicas e de solos, garantindo a manutenção da história de sua evolução em termos de velocidade e magnitude. Como menciona a Declaração Internacional dos Direitos à Memória da Terra (Digne, 1991), "da mesma forma como uma velha árvore registra em seu tronco a memória de seu crescimento e de sua vida, assim também a Terra guarda a memória do seu passado... Uma memória gravada em níveis profundos ou superficiais. Nas rochas, nos fósseis e nas paisagens, a Terra preserva uma memória passível de ser lida e decifrada".

A promoção do geoturismo pode ter a capacidade de potencializar a geoconservação a partir dos sítios com relevante importância como as formações geológicas e os processos geomorfológicos e pedológicos associados, através dos quais é possível a observação e o estudo da história da Terra. Cabem nesta perspectiva, os areais e os processos de arenização, conceitos estes estruturados por Suertegaray (1987), a partir da análise crítica do conceito de desertificação que vinha sendo utilizado para definir tais áreas no sudoeste do Rio Grande do Sul. A autora sistematizou os processos que ocorrem nestas áreas, através da construção do conceito de arenização, que passou a ser entendido como

\section{“(...) o retrabalhamento de depósitos arenosos pouco ou nada consolidados e que promove, nessas áreas, uma dificuldade de fixação de vegetação devido à constante mobilidade dos sedimentos." (Suertegaray, 1987)}

Entende-se, portanto, que o processo de formação dos areais na região em questão é a arenização. Suertegaray e Verdum (2008) ampliaram este conceito, que passou a ser compreendido como

"O retrabalhamento desses depósitos, no caso de formações superficiais, provavelmente quaternárias, resultou de uma dinâmica morfogenética onde os processos hídricos superficiais, particularmente 
o escoamento concentrado do tipo ravina ou voçoroca, associados às chuvas torrenciais, expõe, transporta e deposita areia, dando origem à formação de areais que, em contato com o vento, tendem a uma constante remoção." (Suertegaray, Verdum, 2008)

Quanto aos aspectos de interesse na geoconservação associados aos areais e à arenização, destacam-se as pesquisas efetuadas pelo grupo de pesquisa Arenização/Desertificação: Questões Ambientais, da Universidade Federal do Rio Grande do Sul, como Bellanca (2002), Freitas (2006, 2010), Silva (2008), Mandião (2012) e Vieira (2014), no que se refere à conservação da fauna e flora específicas neste meio, às dinâmicas geomorfológicas ali presentes e à existência de sítios arqueológicos de comunidades indígenas compostos de materiais líticos e cerâmicos.

Considerando os elementos apresentados, o presente trabalho tem por objetivo estabelecer as relações entre o processo de arenização, seu aproveitamento turístico enquanto patrimônio geomorfológico e os conflitos ambientais ocasionados pelo modelo econômico dominante, na bacia hidrográfica do arroio Inhacundá, município de São Francisco de Assis, RS.

\section{1. Área de estudo}

A área definida para a presente pesquisa é a bacia hidrográfica do arroio Inhacundá, em especial a formação geomorfológica denominada de Cerro da Esquina, com a presença de areal e, por conseguinte, a existência dos processos de arenização associados, no município de São Francisco de Assis, na porção Oeste do estado do Rio Grande do Sul, Brasil, como pode ser observado nas figuras 1 e 2.

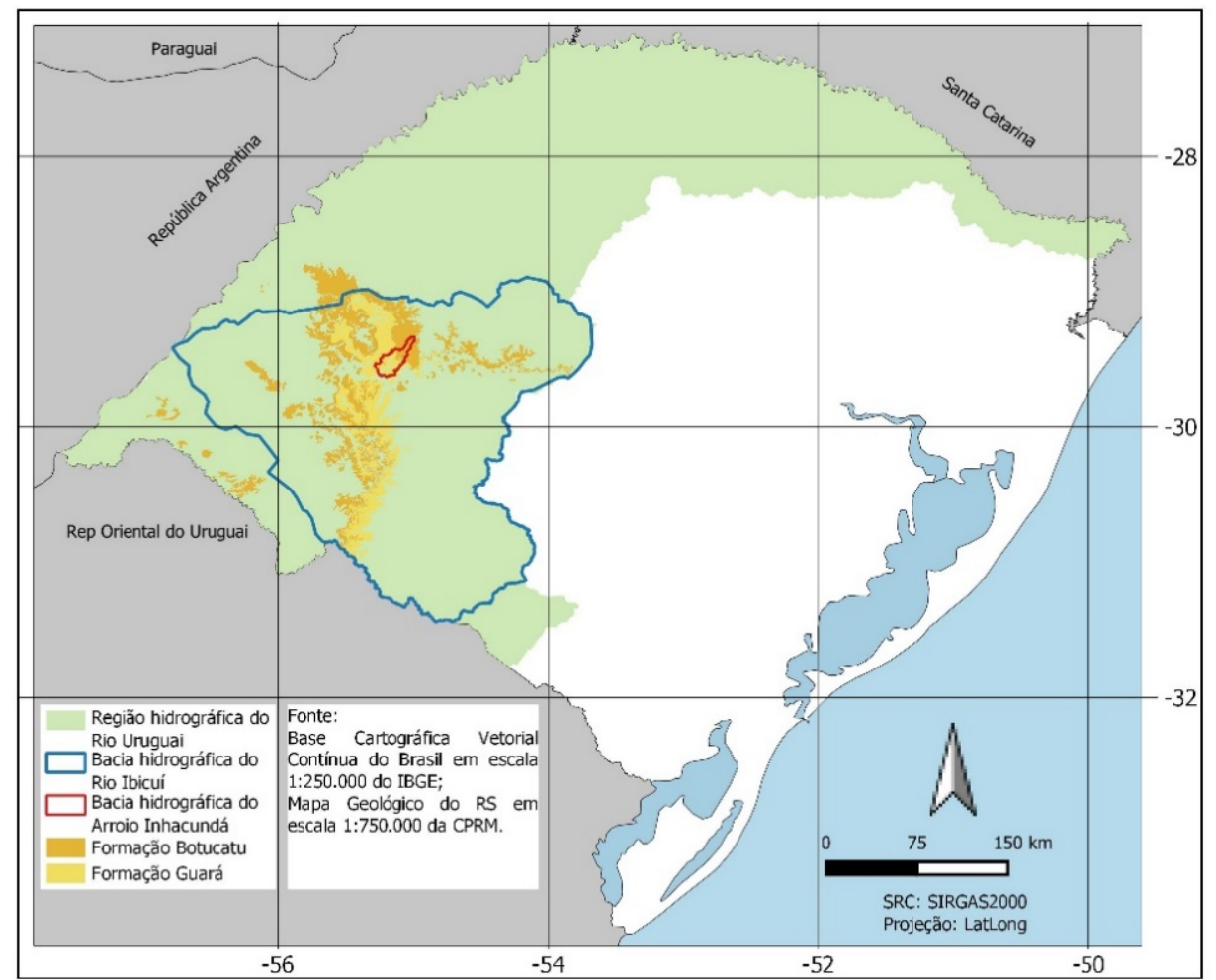

Figura 1: Localização da Bacia Hidrográfica do Arroio Inhacundá, São Francisco de Assis, RS.

Fonte: elaborado pelos autores. 


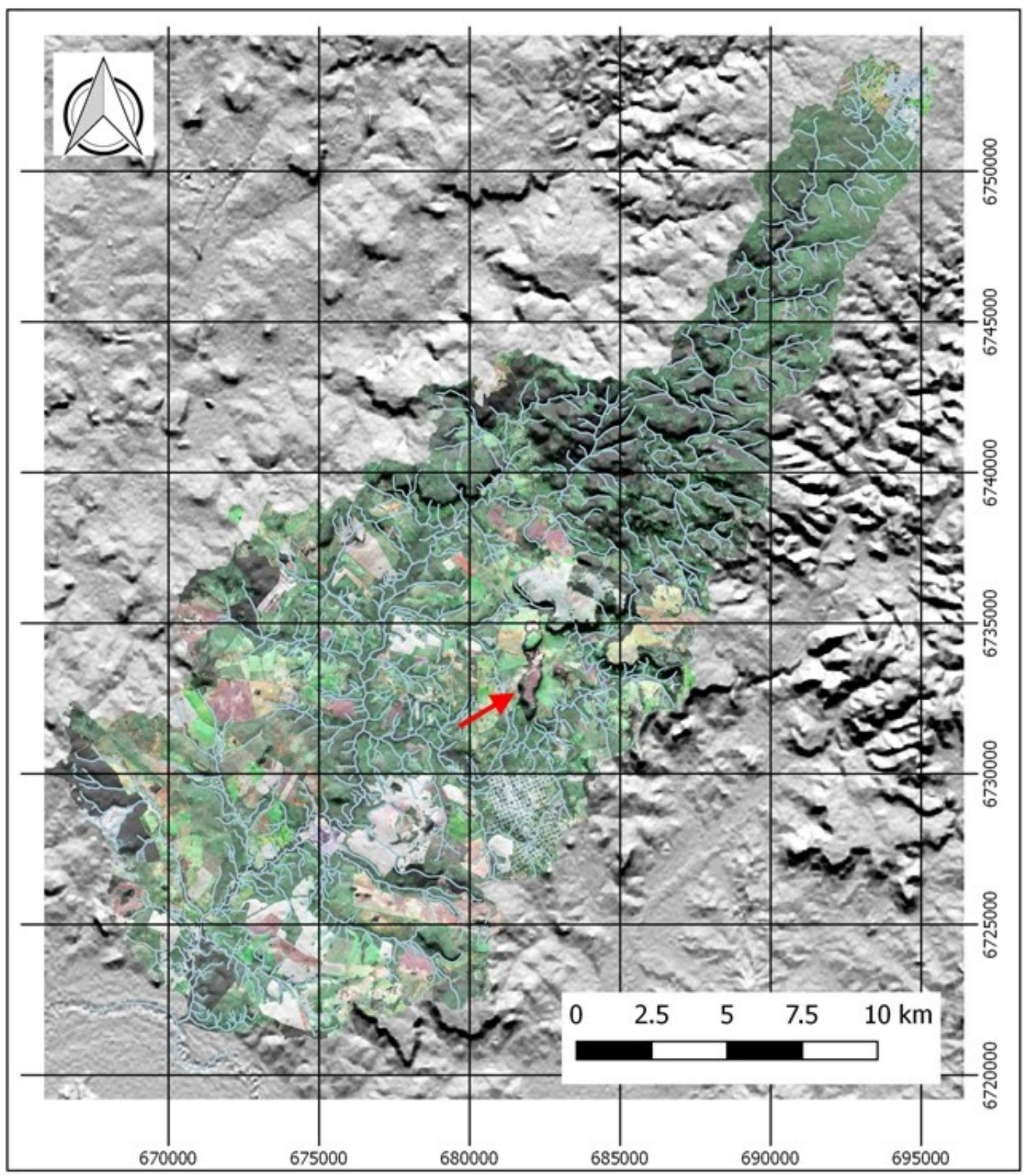

Figura 2: A bacia hidrográfica do arroio Inhacundá e o Cerro da Esquina, São Francisco de Assis, RS.

Fonte: elaborado pelos autores a partir de imagens do Satélite Sentinel-2 e de dados SRTM.

A compartimentação geomorfológica do Rio Grande do Sul, considerando seu segundo táxon, ou seja, as unidades morfoesculturais da metodologia apresentada por Ross (2014), tem sido apresentada em várias propostas de delimitação, desde a década de 1970. A grande questão a ser considerada nestas propostas é o refinamento quanto à escala cartográfica adotada, pois a partir de refinamentos escalares para escalas maiores de análise pode haver distorções e, em alguns casos, enquadramentos equivocados de determinadas feições do relevo. Neste sentido, esta 
metodologia de compartimentação do relevo foi considerada nesta pesquisa, mas com adaptações quanto aos refinamentos escalares para a área de estudo, evitando, assim, distorções quanto a sua localização e conceituação.

No mapa da figura 1, está representada a área de ocorrência das formações geológicas Guará e Botucatu, às quais estão associadas, em grande parte, os processos de arenização. A formação Botucatu é constituída basicamente de arenitos finos e grosseiros, quartzosos e localmente feldspáticos, bem selecionados com cores em tons avermelhados (Machado, 2005), enquanto a formação Guará é caracterizada por arenitos beges e esbranquiçados, com granulometria fina e média, por vezes fina com matriz argilosa, compostos principalmente por quartzo e subordinadamente feldspato (Scherer, Lavina, 2006).

Guasselli et al. (2010) identificaram que 98,52\% dos areais mapeados estão vinculados a essas duas formações ou sobre depósitos quaternários associados às mesmas. Essa associação se deve ao fato de que essas formações foram soerguidas a partir da neotectônica (Trainini, 2005). A partir do soerguimento, as formações foram retrabalhadas pelas dinâmicas climáticas do Quaternário, dando origem a duas formações superficiais identificadas por Suertegaray (1987).

Sob o aspecto da sua localização, os areais estão associados à unidade morfoescultural denominada Depressão Sul-rio-grandesne, tanto nos municípios de São Francisco de Assis e Manoel Viana, RS, na qual se localiza a área objeto do presente estudo, como sobre a unidade morfoescultural denominada de Cuesta do Haedo, mais a sudoeste, nos municípios de Quaraí e Alegrete, RS. Além disso, segundo Suertegaray (2012), os areais estão localizados em baixas altitudes e declividades, sendo comum em médias coxilhas ou rampas em contato com a escarpa dos cerros, como é o caso do Cerro da Esquina.

Mapas geomorfológicos disponíveis para o Estado do Rio Grande do Sul (IBGE, 1986; Dantas et al., 2010), contudo, representam a região da bacia hidrográfica do arroio Inhacundá como pertencente a unidade geomorfológica do Planalto de Uruguaiana. Assim, por questões metodológicas, optou-se em apresentar a área de estudo, em relação às unidades geomorfológicas, entre a escarpa do Planalto de Uruguaiana e a Depressão Periférica Gaúcha; com predomínio de andesitos e basaltos (Formação Serra Geral) no Planalto de Uruguaiana e latitos, arenitos finos e quartzo associados às rochas sedimentares oriundas de deposição eólica (Formação Botucatu) e deposição fluvial (Formação Guará) na Depressão Periférica Gaúcha. O mapa da figura 3 apresenta as unidades geomorfológicas (morfoesculturais) apresentadas por Dantas et al. (2010), para o Rio Grande do Sul, demonstrando a diversidade geomorfológica presente no território do estado. 


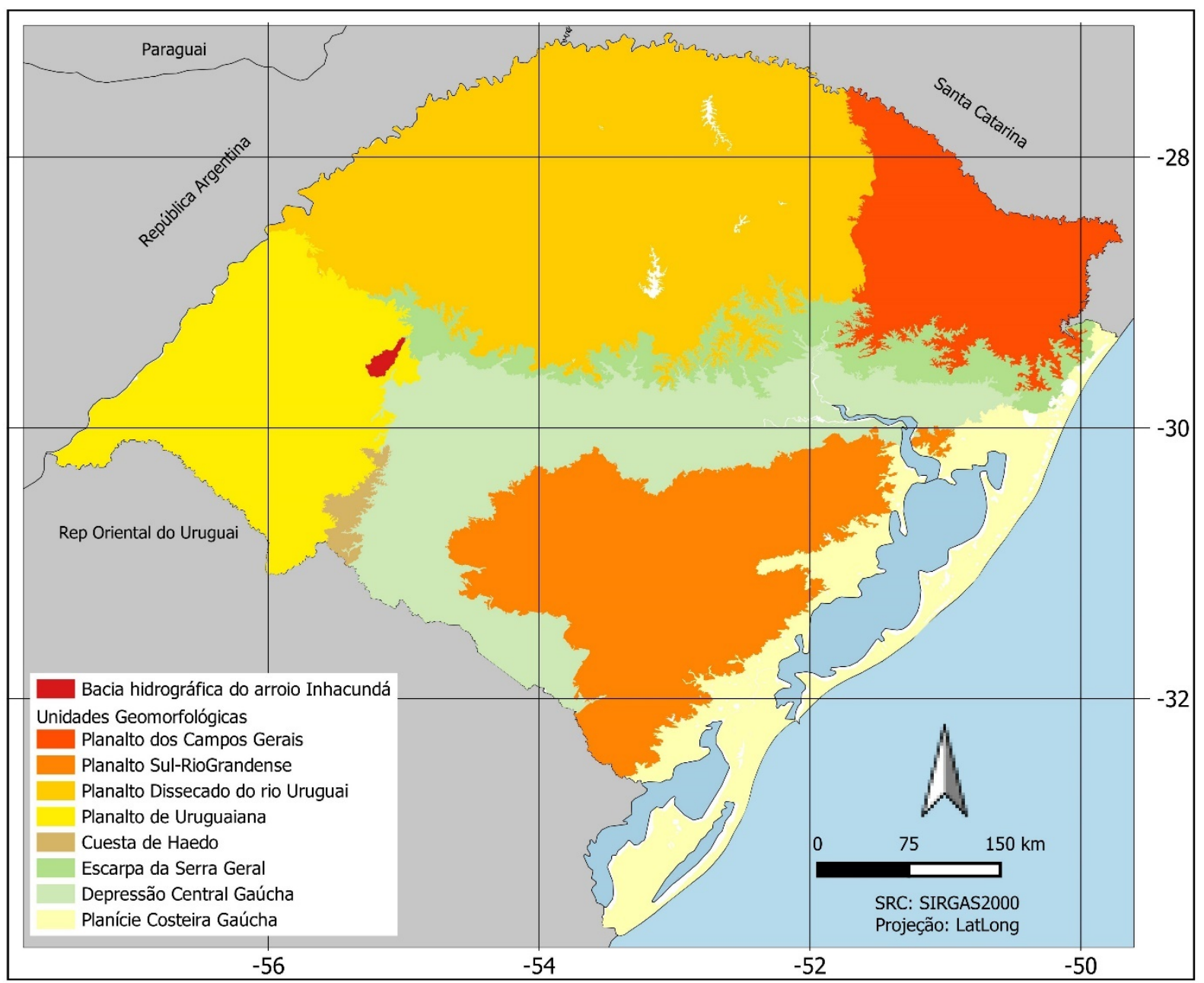

Figura 3: Unidades geomorfológicas do Rio Grande do Sul.

Fonte: adaptado de Dantas et al. (2010).

Oliveira (2015) elaborou uma compartimentação geomorfológica da bacia hidrográfica do arroio Inhacundá, identificando nove compartimentos, com a porção norte da Bacia associada ao Planalto e a porção sul associada à Depressão Periférica. O Cerro da Esquina foi categorizado como Morro Testemunho, com a área do seu entorno estando relacionada aos compartimentos de Encosta, Rampas Arenosas, Coxilhas, além das áreas de Várzea (Oliveira, 2015; Caneppele, 2017). A compartimentação apresentada pode ser visualizada na figura 4 . 


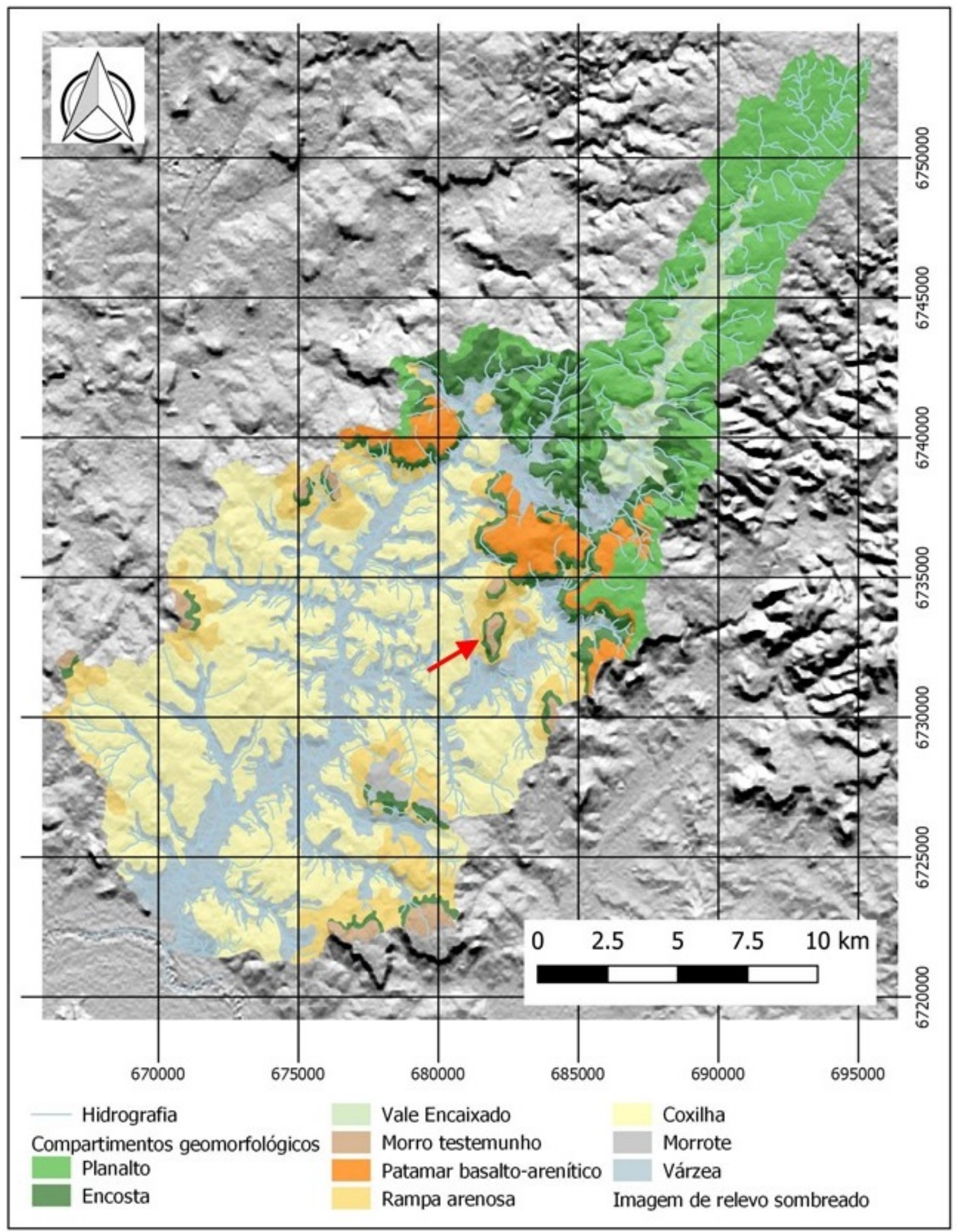

Figura 4: Compartimentação geomorfológica da bacia hidrográfica do arroio Inhacundá. Fonte: Adaptado de Oliveira (2015).

\section{Materiais e métodos}

A discussão do potencial turístico dos processos de arenização, em especial aqueles vinculados ao Cerro da Esquina, ocorreu através da interpretação de dados 
cartográficos e das pesquisas realizadas de longo tempo nesta área. Os dados utilizados para a análise foram a Base Cartográfica Vetorial Contínua em escala 1:25.000 do RS, disponibilizada pela SEMAI-RS (2018), imagens do Satélite Sentinel2, com 10 metros de resolução espacial, do dia 01/04/2019, acessadas através da plataforma LandViewer, disponível no endereço https://eos.com/landviewer, dados altimétricos e relevo sombreado gerados a partir dos dados SRTM processados pelo projeto TopoData do INPE, os limites dos imóveis rurais foram obtidos através da consulta pública da plataforma do Cadastro Ambiental Rural, disponível no endereço http://www.car.gov.br/publico/imoveis/index, com data base de 10/04/2019.

Para a análise a que se propõe o estudo, foram necessários dados de uso e cobertura da terra. Para esta temática, foram utilizados os dados processados pelo projeto MapBiomas, disponíveis na plataforma www.mapbiomas.org. Este projeto utiliza imagens da constelação Landsat para a geração de mapas de uso e cobertura da terra para o período de 1985 a 2017, os quais são disponibilizados gratuitamente e auxiliam na análise temporal pois são baseados numa metodologia única para todo o período. Para o presente estudo, foram utilizados dados de 1985, 1995, 2005 e 2017 para que fosse possível estabelecer um processo evolutivo das formas de apropriação e dos usos para a área em questão.

\section{Resultados e discussão}

Segundo Verdum (2012), o conceito que poderia traduzir a presença de areais e as formas de apropriação e uso na região sudoeste do RS, ao longo do tempo histórico, é a diversidade. Assim, nesta região próxima às fronteiras com o Uruguai e a Argentina, os relevos levemente ondulados, denominados de coxilhas, foram originalmente cobertos pela vegetação herbácea nativa, característica do Bioma Pampa. Junto às margens dos cursos de água, encontram-se os fragmentos de mata nativa, denominados de capões e, cobrindo as encostas dos relevos residuais areníticos, há uma diversidade de espécies vegetais de porte arbóreo, arbustivo, rupícolas, trepadeiras, cactáceas, bromeliáceas, dentre outras.

Neste sentido, a densidade e a diversidade de cobertura vegetal estão naturalmente associadas à incidência da radiação solar, à exposição ao agente eólico, às características do substrato, à dinâmica pluviométrica, à ocorrência de ravinas e voçorocas, assim como à formação de areais consolidados. O Cerro da Esquina se torna assim um local que agrega e exemplifica as questões anteriormente mencionadas, como demonstra a figura 5 .

Vieira (2014), identifica as paisagens portadoras de belezas cênicas a partir de entrevistas com pesquisadores e técnicas que estudam o Pampa há mais de dez anos. Nessa pesquisa, são citados dez areais como possíveis áreas de proteção ambiental, sendo destaque para o areal que se encontra próximo ao Cerro da Esquina.

A vegetação de porte arbóreo-arbustivo ocorre associada às encostas dos cerros com menor incidência solar, voltadas, sobretudo, para o quadrante sul, enquanto àquelas que possuem maior incidência são compostas por afloramentos rochosos e vegetação 
arbustiva-herbácea, voltadas, em grande parte, ao quadrante norte. Nas rampas arenosas e coxilhas, ocorre a vegetação herbácea, utilizada historicamente para o desenvolvimento da pecuária.

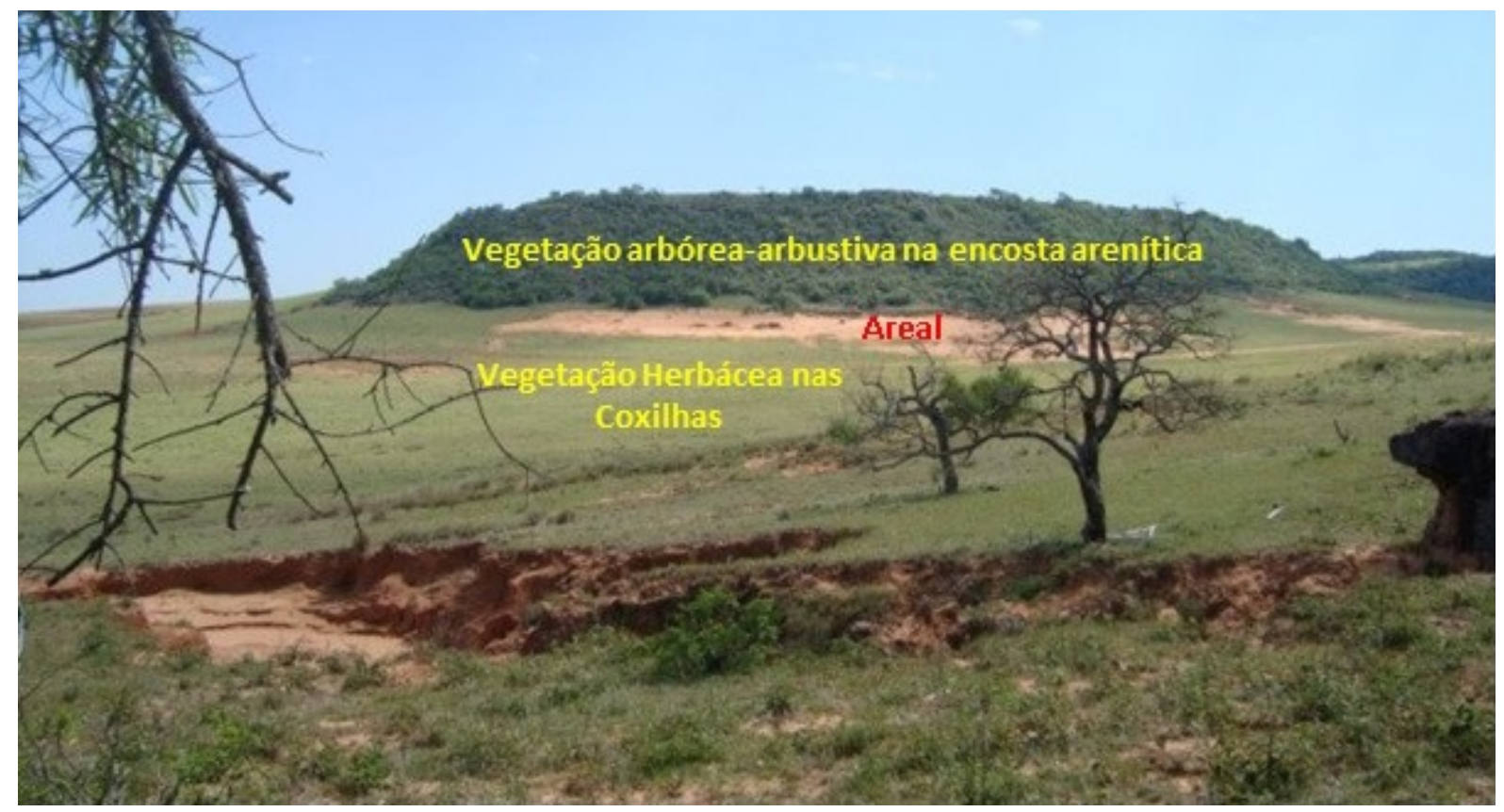

Figura 5: Cerro com encosta arenítica e vegetação arbórea-arbustiva, com areal ancorado e vegetação herbácea nas coxilhas e rampas arenosas, Cerro da Esquina.

Fonte: acervo pessoal (2011).

As dinâmicas de retrabalhamento da arenização podem também ser visualizadas na área de estudo, com a visualização dos focos da arenização nas feições de ravinas e voçorocas que inicialmente estão ligadas à dinâmica pluviométrica de chuvas torrenciais, que podem atingir mais de $100 \mathrm{~mm} /$ dia. Além disso, podem ser visualizados também areais e leques de dejecção que são expostos e retrabalhados pelo agente eólico, como pode ser verificado na figura 6 .

A despeito da sua aparência assemelhada ao meio desértico e estéril, incapaz de sustentar comunidades vegetais, verifica-se, ao contrário, um banco de sementes com significativa diversidade florística no entorno de focos de arenização, sobre taludes de ravinas, ao longo dos canais de voçorocas e na camada superficial do solo, junto às áreas de contribuição aos processos avançados de erosão hídrica (Freitas, 2010; Silva, 2008). 
Os areais do sudoeste do Rio Grande do Sul, Brasil, como patrimônio geomorfológico Geoconservação e Património Natural
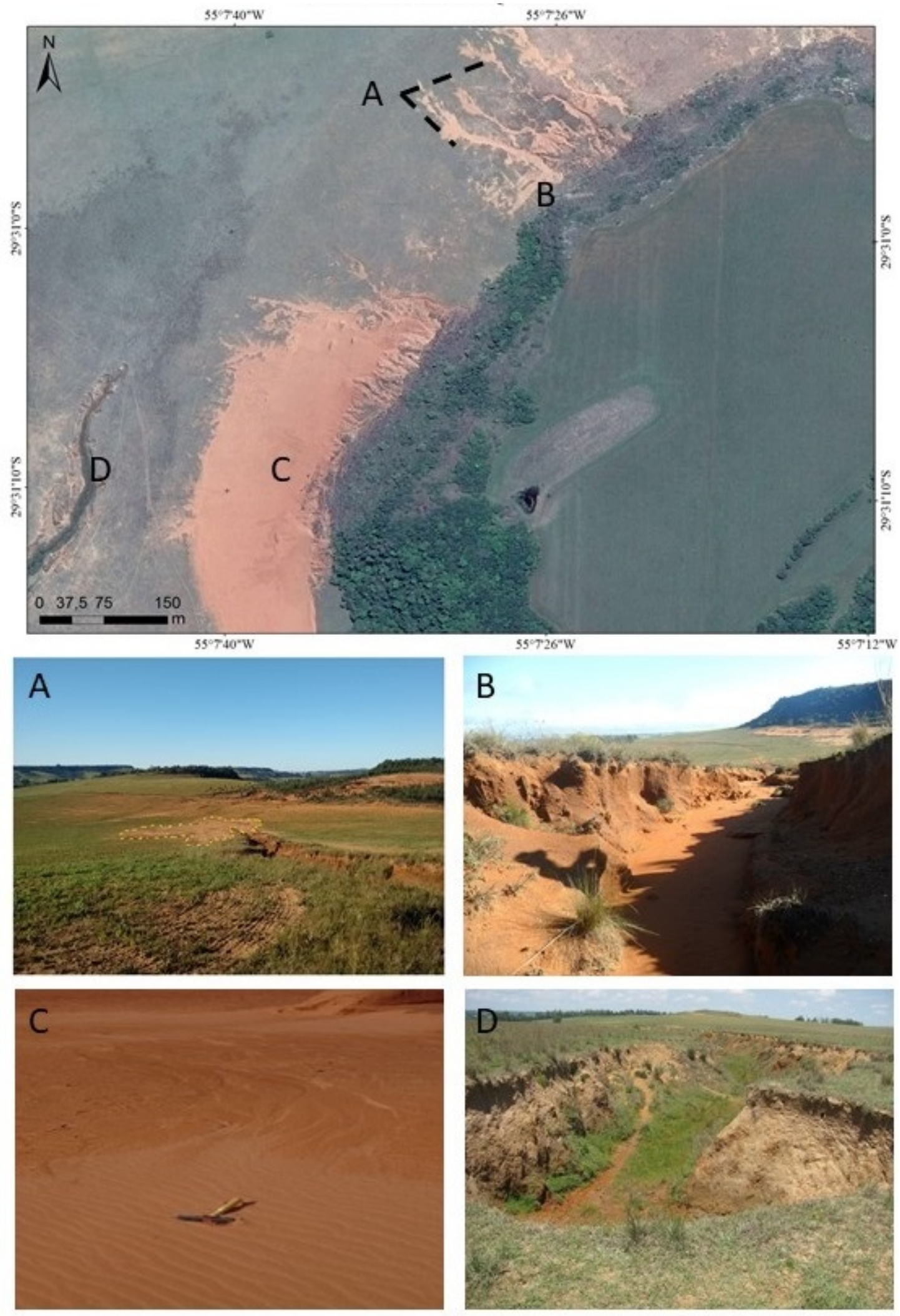

Figura 6: Imagem de Satélite CNES/Astrium do ano de 2012 e fotografias das feições da arenização associadas ao Cerro da Esquina: A - Leques de Dejecção; B - Ravinas; C - Areal e feições eólicas (ripple marks); D - Voçoroca.

Fonte: acervo pessoal dos autores (2011). 
O avanço de monocultivos sobre os areais do RS tem ignorado o imenso potencial de uso e conservação das espécies vegetais nativas endêmicas da região, sendo a maior parte delas desconhecida em suas propriedades alimentícias, medicinais, ornamentais, aromáticas, condimentares e biotécnicas para emprego em projetos de recuperação de áreas degradadas. Esta realidade pode ser visualizada nas tabelas I e II, a partir dos dados de uso e cobertura da terra processados pelo projeto MapBiomas, para o período de 1985 a 2017.

Na tabela I, que se refere ao uso e à cobertura da terra na bacia do arroio Inhacundá (em torno de 36 mil hectares) nos anos de 1985 e 1995, pode-se verificar que próximo de $51 \%$ da cobertura vegetal era composta por vegetação herbácea, que caracteriza o campo nativo; $24 \%$ de cultivos anuais e perenes; $19 \%$ de extrato florestal, não havendo registro de cultivos arbóreos (florestas plantadas) para fins comerciais até este período.

Tabela I: Uso e cobertura da terra na bacia hidrográfica do arroio Inhacundá nos anos de 1985 e 1995.

\begin{tabular}{l|r|r|r|r}
\hline \multirow{2}{*}{\multicolumn{1}{c}{ CLASSES DE USO }} & \multicolumn{2}{c|}{ Ano de 1985 } & \multicolumn{2}{c}{ Ano de 1995 } \\
\cline { 2 - 5 } & \multicolumn{1}{c}{ AREA } \\
\cline { 2 - 5 } & \multicolumn{1}{c}{ ha } & \multicolumn{1}{c}{ ha } & \multicolumn{1}{c}{ ha } \\
\hline Formação florestal & \multicolumn{1}{c|}{$6,005.43$} & 16.62 & $6,569.46$ & 18.18 \\
\hline Floresta plantada & & & & \\
\hline Área úmida natural não florestada & & & 0.63 & 0.00 \\
\hline Formação campestre & $18,029.13$ & 49.89 & $18,303.51$ & 50.65 \\
\hline Pastagem & 508.23 & 1.41 & 482.66 & 1.34 \\
\hline Cultura anual e perene & $9,255.64$ & 25.61 & $8,555.87$ & 23.68 \\
\hline Mosaico de agricultura e pastagem & $2,098.52$ & 5.81 & $1,929.02$ & 5.34 \\
\hline Infraestrutura urbana & 187.83 & 0.52 & 220.26 & 0.61 \\
\hline Outra área não vegetada & 41.63 & 0.12 & 64.75 & 0.18 \\
\hline Rios & 10.59 & 0.03 & 10.84 & 0.03 \\
\hline Total & $36,137.00$ & 100.00 & $36,137.00$ & 100.00 \\
\hline
\end{tabular}

Fonte: elaborado a partir dos dados do projeto MapBiomas.

Na tabela II, que se refere ao uso e à cobertura da terra na bacia do arroio Inhacundá nos anos de 2005 e 2017, pode-se verificar que em relação à cobertura vegetal composta pela vegetação herbácea, houve a redução de 3\%, entre 1985 e 2017; a redução em torno de $4 \%$ de cultivos anuais e perenes; a redução de $1 \%$ de extrato florestal e o plantio em torno de 807 hectares de cultivos arbóreos, que representam em torno de $2 \%$ da bacia do arroio Inhacundá. 
Tabela II: Uso e cobertura da terra na bacia hidrográfica do arroio Inhacundá nos anos de 2005 e 2017.

\begin{tabular}{|c|c|c|c|c|}
\hline \multirow{3}{*}{ CLASSES DE USO } & \multicolumn{2}{|c|}{ Ano de 2005} & \multicolumn{2}{|c|}{ Ano de 2017} \\
\hline & \multicolumn{4}{|c|}{ AREA } \\
\hline & ha & $\%$ & ha & $\%$ \\
\hline Formação florestal & $6,085.90$ & 16.84 & $6,422.56$ & 17.77 \\
\hline Floresta plantada & & & 806.77 & 2.23 \\
\hline Área úmida natural não florestada & 0.90 & 0.00 & 7.12 & 0.02 \\
\hline Formação campestre & $17,403.32$ & 48.16 & $17,108.91$ & 47.34 \\
\hline Pastagem & 570.43 & 1.58 & 546.05 & 1.51 \\
\hline Cultura anual e perene & $7,980.38$ & 22.08 & $7,193.22$ & 19.91 \\
\hline Mosaico de agricultura e pastagem & $3,763.93$ & 10.42 & $3,749.41$ & 10.38 \\
\hline Infraestrutura urbana & 273.65 & 0.76 & 264.60 & 0.73 \\
\hline Outra área não vegetada & 53.78 & 0.15 & 22.15 & 0.06 \\
\hline Rios & 4.71 & 0.01 & 16.21 & 0.04 \\
\hline Total & $36,137.00$ & 100.00 & $36,137.00$ & 100.00 \\
\hline
\end{tabular}

Fonte: elaborado a partir dos dados do projeto MapBiomas.

No que se refere aos areais que se desenvolvem pela associação da ação erosiva hídrica com a eólica, os dados do projeto MapBiomas não apresentam nenhuma quantificação, pois incorporam tais áreas nos dados referentes a "outras áreas não vegetadas", na qual são consideradas todas as áreas de solo exposto. Contudo, através das imagens da figura 7 , é possível visualizar que os areais têm mantido certa estabilidade, ocorrendo variações sazonais. A principal alteração observada é a introdução de espécies arbóreas exóticas (Eucalyptus sp.), com o intuito de "conter o processo de arenização", como demonstra a Figura 8.

Assim, considerando os aspectos da especificidade em termos de fauna e flora existentes no interior e no entorno dos areais, conforme Silva (2008) e Freitas et al. (2009), verifica-se como atrativo de interesse científico e geoturístico a significativa biodiversidade. Conforme os autores, as espécies dominantes são gramíneas reptantes típicas dos campos que caracterizam a fisionomia do Pampa e a base do pastoreio, representadas principalmente por Paspalum stellatum, $P$. nicorae e $P$. notatum. Neste sentido, apesar dos areais serem considerados como produto entre os limitantes do potencial geoecológico e o impacto tecnológico da(s) sociedade(s) local(is) sobre a biomassa dos campos do Pampa, Verdum e Suertegaray (2012) destacam que estes representam ecossistemas testemunhos, que integram constantes adaptações da vida animal e vegetal às variações climáticas do planeta, ao longo de sua história geológica recente (Quaternário), e às intervenções sociais históricas. Neste sentido, os areais podem ser considerados, também, como atrativos de interesse científico no âmbito das propostas de conservação ambiental e geoturismo. 


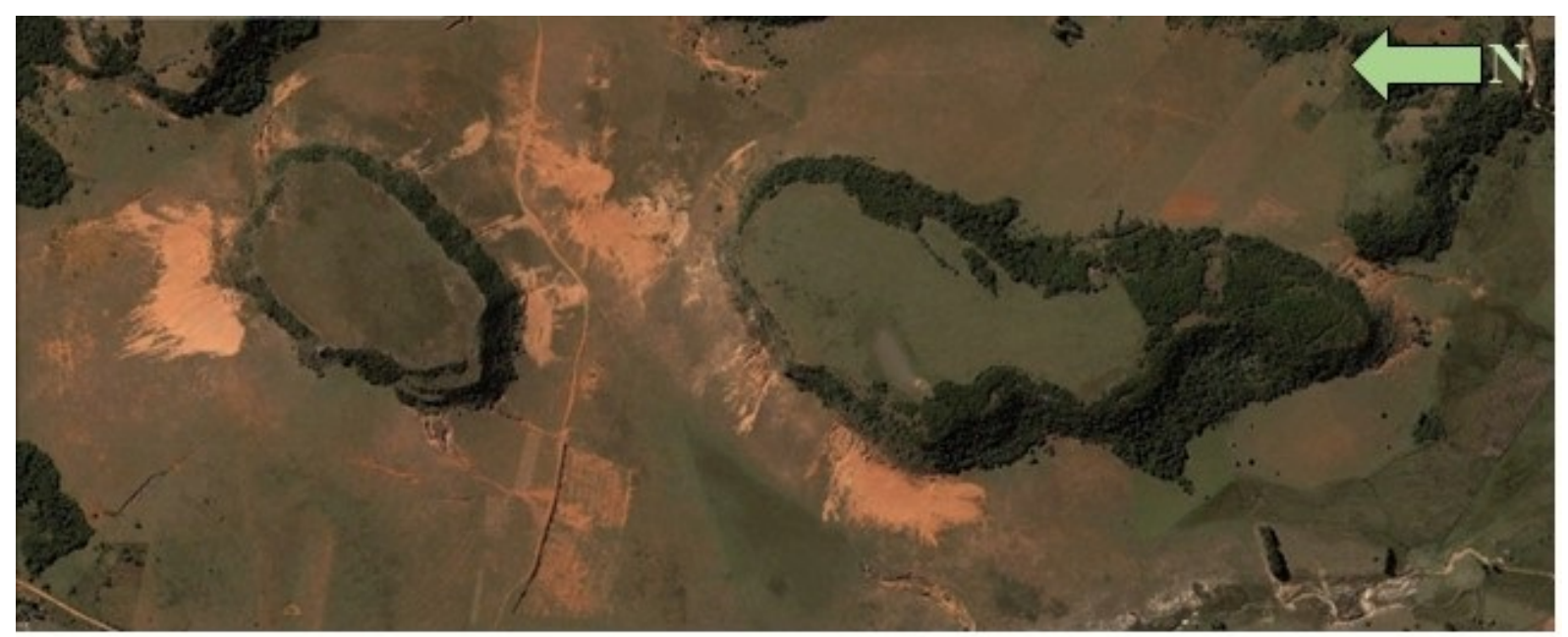

26/04/2004 - Maxar Technologies / NASA - Fonte: GoogleEarth

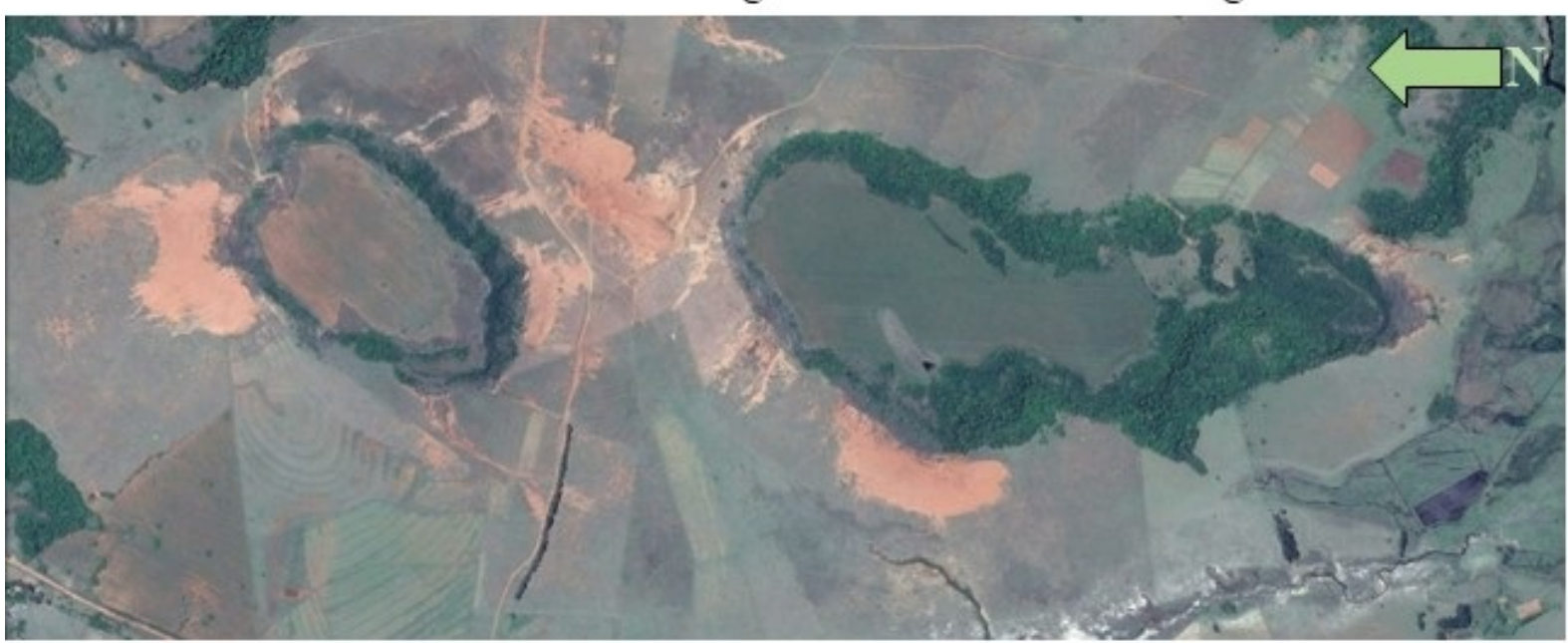

30/09/2013 - CNES / Airbus - Fonte: GoogleEarth

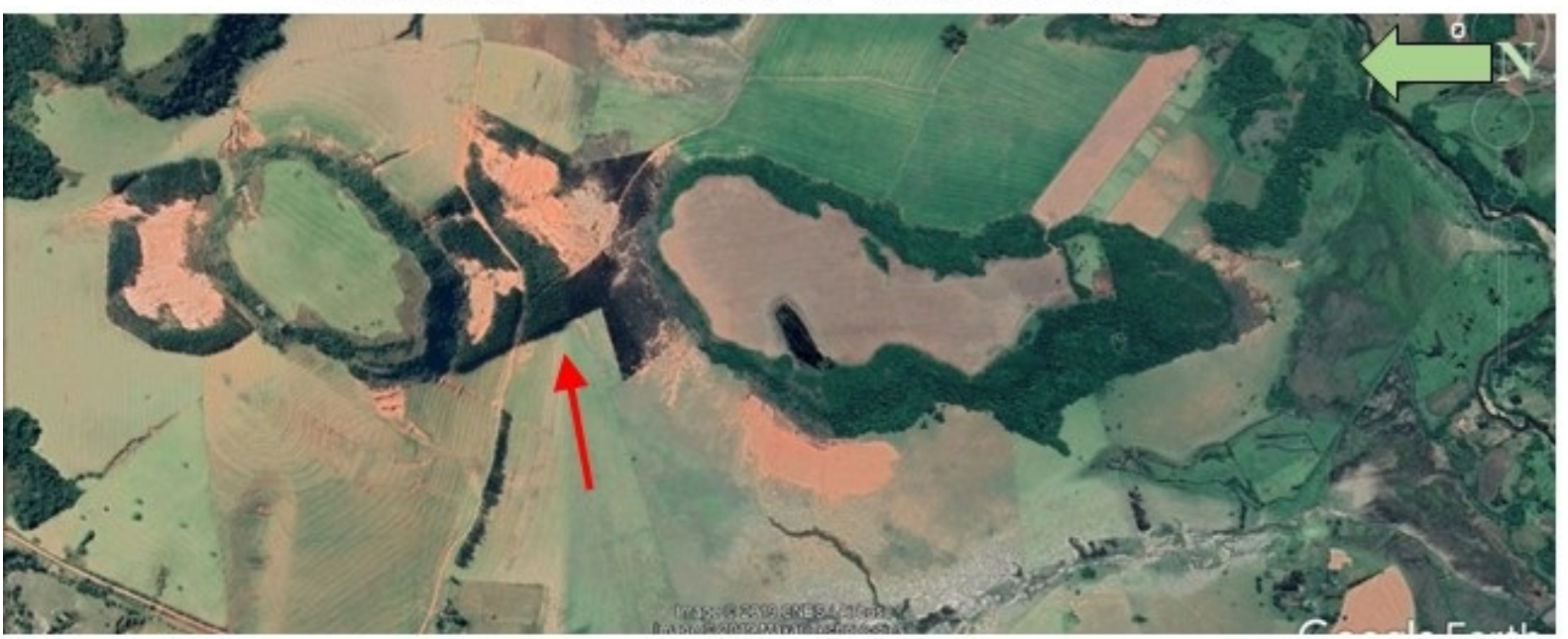

1/11/2018 - CNES / Airbus - Fonte: GoogleEarth

Figura 7: Evolução dos areais no Cerro da Esquina.

Fonte: elaborado pelos autores a partir de imagens de satélite disponíveis no GoogleEarth. 


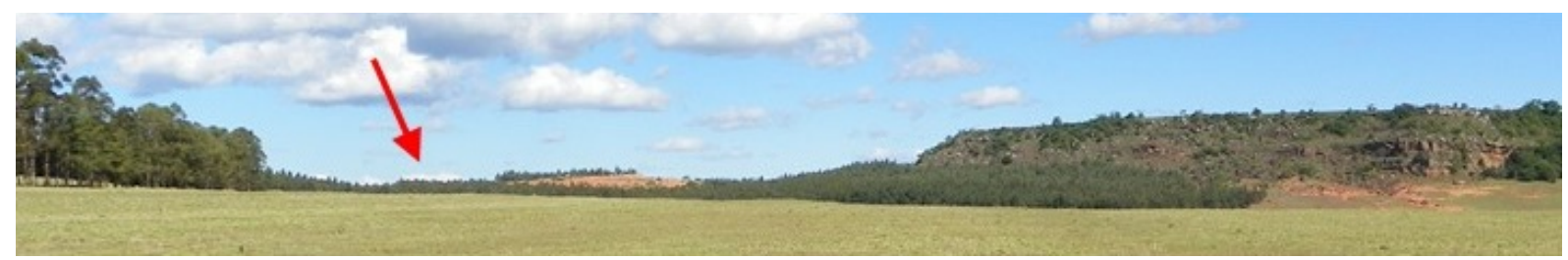

Figura 8: Implantação de plantio de Eucalyptus sp. em áreas de arenização no Cerro da Esquina.

Fonte: arquivo pessoal dos autores (2017).

Vieira (2014) cita que os areais são redutos do passado, desde um tempo histórico longo, além de ser uma paisagem pitoresca, ou seja, caracterizada pela sua raridade, complexidade, excentricidade e possui um contraste singular, uma quebra de monotonia do verde dos campos, entre colinas. morros testemunhos, ravinas, voçorocas e vales aluviais.

Vieira (2014, p. 217) também explica que:

\begin{abstract}
As belezas cênicas das paisagens possuem importância a nível social, cultural, histórico, econômico e ecologicamente. Muitas, ao lembrar o passado, fortalecem o sentimento identitário; conectam as pessoas à natureza e ao universo; produzem qualidade de vida e bem estar social, relaxamento, paz interior e elevação espiritual; por serem reais, são independentes de qualquer convenção, possuem valor intrínseco, seja financeiro, seja utilitário; apresentam atributos raros, elementos singulares da natureza; são permeadas de cultura, contribuindo na reprodução social e no modo de vida das comunidades.
\end{abstract}

\title{
Considerações finais
}

A arenização, concebida como um processo único no contexto das dinâmicas geomorfológicas no espaço geográfico subtropical do sul do Brasil, e os areais como resultado deste processo, podem ser considerados como potencial patrimônio geomorfológico e geoturístico. No entanto, assim como se ampliam os conflitos ambientais ocasionados pelo modelo econômico sobre a biodiversidade e sociodiversidade no Pampa, também em relação aos areais há uma forte pressão no sentido de considerá-los como mera degradação ambiental e passíveis de serem eliminados. Neste contexto, afirma-se, inclusive, que se poderá conter e até eliminar os areais com o plantio de espécies vegetais arbóreas exóticas, prioritariamente o eucalipto (Eucalyptus $s p$.), acabando assim com uma problemática ambiental identificada desde os anos de 1970.

Dentre os areais que podem ser identificados na região de estudo, encontra-se aquele situado na bacia hidrográfica do arroio Inhacundá, mais especificamente junto à feição geomorfológica denominada Cerro da Esquina. Este possui, por suas especificidades em termos de geo-biodiversidade, um potencial interessante para a exploração geoturística, sobretudo, no que diz respeito ao conhecimento sobre o processo de arenização e a vida ali presente, caracterizada pela existência de animais e vegetais com fisionomias e fisiologias adaptadas tanto às condições climáticas do passado, em condições de semiaridez, como às atuais úmidas, sob a influência de um clima subtropical. 
A propriedade rural onde se situa este areal é identificada como sendo oriunda de uma estrutura fundiária típica de latifúndio, perfazendo uma área em torno de 800 ha, em que historicamente a atividade agrícola até então desenvolvida estava relacionada à pecuária extensiva. Mais recentemente, a partir de 2013, identifica-se o plantio de eucalipto em seu entorno, em detrimento da vegetação campestre com espécies nativas adaptadas às condições do meio e capaz de evitar a sua expansão. Assim, rompe-se de um lado o areal enquanto testemunho de um ecossistema do passado recente na escala de tempo geológico como a dinâmica geomorfológica específica que se desenvolve em seu interior, conectando atributos da ação dos agentes hídrico e eólico no presente e que geram feições geomorfológicas totalmente atípicas. Assim, entende-se que a implantação da monocultura silvícola com espécies exóticas para fins industriais é capaz de interferir no processo de conservação deste patrimônio geomorfológico, bem como reduz o potencial geoturístico de fenômenos raros como este.

\section{Bibliografia}

Belanca, E. T. (2002). Uma contribuição a explicação da gênese dos areais do sudoeste do Rio Grande do Sul. Dissertação de Mestrado. Programa de Pós-Graduação em Geografia, Universidade Federal do Rio Grande do Sul. Porto Alegre, RS. Disponível em 15/04/2019, em: https://lume.ufrgs.br/handle/10183/2685

Bétard, F., Hoblea, F., Portal, C. (2017a). Les géopatrimoines, de nouvelles ressources territoriales au service du développement local. Annales de Géographie, 717, 523-543. http://dx.doi.org/10.3917/ag.717.0523

Bétard, F., Peulvast, J. P., Magalhães, A. O., Freitas, F. I. (2017b). Géopatrimoine et biopatrimoine, à la croisée entre conservation et développement. Une approche des trajectoires patrimoniales dans le Cariri du Ceará (Nordeste brésilien). Annales de Géographie, 717, 544-565. http://dx.doi.org/10.3917/ag.717.0544

Caneppele, J. C. G. (2017). Espacialização da arenização a partir da ecodinâmica e da cartografia ambiental. Dissertação de mestrado. Programa de Pós-Graduação em Geografia, Instituto de Geociências, Universidade Federal do Rio Grande do Sul. Porto Alegre. Disponível em 16/04/2019, em: https://lume.ufrgs.br/handle/10183/171442

Dantas, M. E., Viero, A. C., Silva, D. R. A. da (2010). Origem das paisagens. In: Viero, A. C., Silva, D. R. A. da. Geodiversidade do Estado do Rio Grande do Sul. Porto Alegre: CPRM.

Digne (1991). Carta de Digne - Declaração Internacional dos direitos à memória da Terra. Digne-Les-Bains. Disponível em 15/04/2019, em: http://www.Ineg.pt/CienciaParaTodos/patrimonio/memoria terra

Figueiró, A. S., Ziemann, D. R., Degrandi, S. M., Cecchin, D. N. (2018). Índice de aproveitamento geoturístico e valores da geodiversidade aplicados ao geossítio morro agudo no território da proposta geoparque Quarta Colônia, RS, Brasil. In: Atas do Encontro Luso-Afro-Americano de Geografia Física e Ambiente, II (pp. 1203-1209). Guimarães: Cegot, Universidade do Minho.

Freitas, E. M. (2006). Arenização e fitossociologia da vegetação de campo no município de São Francisco de Assis, RS. Dissertação de mestrado. Programa de Pós-Graduação em 
Geografia, Instituto de Geociências, Universidade Federal do Rio Grande do Sul. Porto Alegre, RS. Disponível em 16/04/2019, em: https://www.lume.ufrgs.br/handle/10183/7372

Freitas, E. M. (2010). Campos de solos arenosos do sudoeste do Rio Grande do Sul: Aspectos florísticos e adaptativos. Tese de doutorado. Programa de Pós-Graduação em Botânica, Instituto de Biociências, Universidade Federal do Rio Grande do Sul. Porto Alegre, RS. Disponível em 16/04/2019, em: https://lume.ufrgs.br/handle/10183/26295

Freitas, E. M. de, Boldrini, I. I., Muller, S. C., Verdum, R. (2009). Florística e fitossociologia da vegetação de um campo sujeito à arenização no sudoeste do Estado do Rio Grande do Sul, Brasil. Acta Botanica Brasilica, 23(2), 414-426. http://dx.doi.org/10.1590/S0102$\underline{33062009000200013}$

Guasselli, L. A., Suertegaray, D. M. A., Oliveira, M. G., Sirangelo, F., Evers, H. (2010). Relação entre a ocorrência de areais e os arenitos da Formação Botucatu e Guará, no sudoeste do estado do Rio Grande do Sul, Brasil. In: VII Simpósio Nacional de Geomorfologia. Recife: UFPE/PPGEO.

IBGE (1986). Folha SH.22 Porto Alegre e parte das Folhas SH.21 Uruguaiana e SI.22 Lagoa Mirim: geologia, geomorfologia, pedologia, vegetação, uso potencial da terra. Rio de Janeiro: IBGE.

Machado, J. L. F. (2005). Compartimentação espacial e arcabouço hidroestratigrafico do Sistema de Aquífero Guarani no Rio Grande do Sul. Tese de doutorado, Programa de Pós Graduação em Geologia, Unisinos. Porto Alegre.

Mandião, A. G. (2012). Campos e areais no sudoeste do RS, subsídio para a criação de unidades de conservação. Dissertação de Mestrado em Geografia, Universidade Federal do Rio Grande do Sul. Porto Alegre. Disponível em 15/04/2019, em: https://www.lume.ufrgs.br/handle/10183/67652

Mansur, K. L. (2018). Patrimônio geológico, geoturismo e geoconservação: uma abordagem da geodiversidade pela vertente geológica. In: Guerra, A. J. T., Jorge, M. do C. O. (org.) Geoturismo, geodiversidade, geoconservação: abordagens geográficas e geológicas. (pp. 1-49). São Paulo: Oficina de Textos.

Newsome, D., Dowling, R. (2006). The scope and nature of geoturism. In: Dowling, R., Newsome, D. (ed.) Geoturism. (pp. 3-25). Oxford: Elsevier; Butterworth; Heinemann.

Oliveira, M. G. (2015). Análise morfopedológica da Bacia Hidrográfica do Arroio Inhacundá (RS). Dissertação de mestrado, Programa de Pós Graduação em Geografia, Instituto de Geociências, Universidade Federal do Rio Grande do Sul. Porto Alegre, RS. Disponível em 14/04/2019, em: https://lume.ufrgs.br/handle/10183/133652

Peixoto, C. A. B. (2015). Caracterização Ambiental dos goessítios da proposta: projeto geoparque Guaritas - Minas do Camaquã / RS. Dissertação de Mestrado em Geografia, Universidade Federal do Rio Grande do Sul. Porto Alegre. Disponível em 16/04/2019, em: https://lume.ufrgs.br/handle/10183/128898

Peixoto, C. A. B. (2017). Geoparque Guaritas - Minas do Camaquã: proposta. Porto Alegre: CPRM.

Ross, J. L. S. (2014). Geomorfologia: ambiente e planejamento. 9. ed. São Paulo: Contexto. 
Scherer, C. M. S., Lavina, E. L. C. (2006). Stratigraphic evolution of fluvial-eolian sucession: the example of the Upper Jurassic-Lower Cretaceous Guará and Botucatu formations, Paraná Basin, Southern Brazil. Gondwana Research, 9(4), 475-484. https://doi.org/10.1016/j.gr.2005.12.002

Schobbenhaus, C., Campos, D. de A., Queiroz, E. T. de, Winge, M., Berbert-Born, M. (2002). Sítios geológicos e paleontológicos do Brasil - Volume I. Brasília: CPRM.

Schobbenhaus, C., Silva, C. R. da (2012). Geoparques: propostas do Brasil - volume 1. Brasília: CPRM.

SEC-RS (2017). Regionalização turística 2017. Disponível em: https://cultura.rs.gov.br/regionalizacao-turistica-2017

SEMAI-RS (2018). Base Cartográfica do Estado do Rio Grande do Sul, escala 1:25.000. Versão 1.0. Porto Alegre: SEMAI-RS. Disponível em 15/01/2019, em: https://sema.rs.gov.br/cartografia

Sharples, C. (2002). Concepts and principles of geoconservation: version 3. Tasmania Parks and Wildlife Service, 81 p. Disponível em 10/04/2019, em: https://www.researchgate.net/publication/266021113 Concepts and principles of geoco nservation

Silva, L. P. da. (2008). Narrativas das percepções e conectividades de caminhantes nas paisagens dos areais pampeanos: perspectivas ambientais para geração de ambiências. Dissertação de Mestrado em Geografia, Universidade Federal do Rio Grande do Sul. Porto Alegre. Disponível em 15/04/2019, em: https://www.lume.ufrgs.br/handle/10183/15719

Suertegaray, D. M. A. (1987). Deserto grande do sul. Porto Alegre: Editora da UFRGS.

Suertegaray, D. M. A. (2012). Arenização: análise morfogenética. In: Suertegaray, D. M. A., Silva, L. A. P. da, Guasselli, L. A. (Org.) Arenização: natureza socializada. (pp. 127-172). Porto Alegre: Compasso Lugar-Cultura \& Imprensa Livre.

Suertegaray, D. M. A., Verdum, R. (2008). Desertification in the tropics. In: UNESCO (Org.) Encyclopedia of life support systems (EOLSS). Paris: UNESCO Publishing.

Trainini, D. R. (2005). A influência da Neotectônica no assoreamento de Bacias. In: XVI Simpósio Brasileiro de Recursos Hídricos. João Pessoa: ABRH, CD-ROM.

Verdum, R. (2012). Descoberta permanente: das areias aos areais. In: Suertegaray, D. M. A., Silva, L. A. P. da, Guasselli, L. A. (Org.) Arenização: natureza socializada. (pp. 73-83). Porto Alegre: Compasso Lugar-Cultura \& Imprensa Livre.

Verdum, R., Suertegaray, D. M. A. (2012). A morfodinâmica dos areais: os processos e as formas no presente. O tempo que faz (weathering). In: Suertegaray, D. M. A., Silva, L. A. P. da, Guasselli, L. A. (Org.) Arenização: natureza socializada. (pp. 173-183). Porto Alegre: Compasso Lugar-Cultura \& Imprensa Livre.

Vieira, L. de F. dos S. (2014). A valorização da Beleza Cênica da Paisagem do Bioma Pampa do Rio Grande do Sul: Proposição Conceitual e Metodológica. Tese de doutorado, Programa de Pós-Graduação em Geografia, Instituto de Geociências, Universidade Federal do Rio Grande do Sul. Porto Alegre. Disponível em 16/04/2019, em: https://lume.ufrgs.br/handle/10183/106341 
Vieira, L., Verdum, R. (2019). A Proteção da Natureza e do Patrimônio da Humanidade pela Beleza Cênica da Paisagem. Confins, 40. https://doi.org/10.4000/confins.19680

Winge, M., Schobbenhaus, C., Souza, C. R. de G., Fernandes, A. C. S., Berbert-Born, M., Sallun-Filho, W., Queiroz, E. T. de, Campos, D. de A. (2009). Sítios geológicos e paleontológicos do Brasil - Volume II. Brasília: CPRM.

Winge, M., Schobbenhaus, C., Souza, C. R. de G., Fernandes, A. C. S., Berbert-Born, M., Sallun-Filho, W., Queiroz, E. T. de (2013). Sítios geológicos e paleontológicos do BrasilVolume III. Brasília: CPRM.

Ziemann, D. R., Figueiró, A. S. (2017). Avaliação do potencial geoturístico no território da proposta geoparque Quarta Colônia. Revista do Departamento de Geografia, 34, 137-149. https://doi.org/10.11606/rdg.v34i0.135156

Artigo recebido em/ Received on: 10/11/2019

Artigo aceite para publicação em/ Accepted for publication on: 30/12/2019 
Gass et al. / Physis Terrae, Vol. 1, nº 2, 2019, 101-119

Página intencionalmente deixada em branco 